\title{
Assessment of Vitamin and Mineral Intakes in Paralympic Athletes in Tabriz, Iran
}

\author{
Ramin Amirsasan ${ }^{1}$, Vahid Sari Sarraf ${ }^{1}$, Parvane Dolataabadi* ${ }^{*}$ \\ ${ }^{1}$ Associate Professor, Department of Exercise Physiology, School of Physical Education and Sports Science, University of \\ Tabriz, Tabriz, Iran \\ ${ }^{2}$ MSc Student, Department of Exersice Physiology and Sports Nutrition, School of Physical Education and Sports Science, \\ University of Tabriz, Tabriz, Iran
}

\section{*Correspondence to Parvane Dolataabadi, Tel: 09367740902; Email: \\ parvane.dolataabadi1992@gmail.com.}

Received February 6, 2017 Accepted June 15, 2017 Published online September 31, 2017

\begin{abstract}
Introduction: Paralympic games are the most important competitions for disabled people in the world. Nowadays the role of nutrition is undeniable in physical exercises and the deficiency of micronutrients leads to poor performance by athletes, so our aim was to assess vitamin and mineral intakes in elite Paralympic athletes in Tabriz.

Methods: Thirty-five elite Paralympic athletes (24 men and 11 women) took part in this study. Three-day self-reported food diaries were analyzed for vitamins and nutrients and were checked against the dietary reference intakes (DRIs). The Data were analyzed by Shapiro-Wilk, one sample test and independent sample test were used for checking the normality, and were compared with DRIs in terms of the nutrients intake. In addition, a comparison was made between male and female athletes.

Results: The results indicated that the intake of vitamins $E$ and $D$, potassium, fluorine, chromium, molybdenum in all athletes, vitamin $\mathrm{K}$, magnesium, folate in men, and biotin and calcium in women was significantly lower than DRIs $(P<0.05)$. Vitamin A, biotin and calcium in men, pantothenic acid, folate, B2, B12, K, magnesium, sodium intake in women, zinc and manganese intake in all athletes had no significant differences with DRls. However, vitamin B1, B3, B6 and C, phosphorus, copper, iron in all athletes and B2, B12, pantothenic acid \& sodium in men were significantly higher than DRIs $(P<0.05)$.

Conclusion: The intake of several important vitamins and minerals by these Paralympic athletes was lower than the standard value. Given the importance of vitamins and minerals for repairing muscle tissues, recovering in exercises and improving performance in competitive levels, athletes need to pay attention to their diets and improve food choices.

Keywords: Paralympic, Elite, Vitamin, Mineral
\end{abstract}

\section{Introduction}

Disability is the incompetency of physical and mental functions resulting in disability in performing social skills. ${ }^{1}$ Disabled sports have attained special attention in Iran and all around the globe by the quality of international competitions and the results obtained by these athletes. ${ }^{2}$ In order to reach the climax in Paralympic games, athletes require to optimize their training and performance strategies as well as their nutrition. Regarding that, one can easily lose the competition by minor mistakes. The role of nutrition competency is crucial to success. There is a noteworthy body of knowledge regarding the impacts of dietary intakes on individuals' performance; however, there are few studies investigating the micronutrient intake of disabled athletes and individuals. ${ }^{2}$ There have been several studies of dietary intake of athletes with disabilities. ${ }^{3-6}$ Whereas the adverse effects of confined intakes of macronutrients on physical functionality have been noted, not much data is available on the role of dietary vitamin and mineral deficiency in training and performance of disable athletes. ${ }^{7}$ Some vitamins and minerals in athletes are required more than those of normal people. ${ }^{8}$ Lower than standard intake of micronutrients can exert some serious adverse functional disabilities. Megaloblastic anemia results from

Copyright (C) 2017 The Author(s); Published by Zabol University of Medical Sciences. This is an open-access article distributed under the terms of the Creative Commons Attribution License (http://creativecommons.org/licenses/by/4.0), which permits unrestricted use, distribution, and reproduction in any medium, provided the original work is properly cited. 
deficiency in folate or vitamin B12. These vitamins participate in many cellular functions. Appropriate delivery of these vitamins is required to attain desirable physical function during exercises. The micronutrients and vitamins also participate as functional and indispensable components of metabolic enzymes. They play role in regulation of many cellular functions such as energy balance, gas transport, antioxidant capacity, and cellular receptors and signaling. ${ }^{7}$ So, notifying athletes about the vitamin and mineral intakes is a necessity. Since there were no specific recommendations about vitamins and minerals for disabled people, it seems the recommended dietary allowances (RDA) for healthy people can identify some differences with the standard value. However, because the RDA is set at an intake level exceeding the requirements of almost all individuals, an intake below the RDA cannot be assessed as inadequate. ${ }^{3}$ Therefore, our goal was to assess vitamin and mineral intakes in elite Paralympic athletes in Tabriz, North West of Iran.

\section{Methods \\ Participants \\ Thirty-five elite Paralympic athletes (24 men and 11 women), age $\geq 19$ years in different sports fields includ- ing (sitting volleyball, wheelchair basketball, track and field, wheelchair tennis, swimming, cycling, weightlifting, shooting, football 5-a-side) in off-season period in which they were trained 3 times a week, took part in this study. Since there were few elite Paralympic athletes in Tabriz, they were chosen by the availability sampling method. The study protocol was approved by the Iranian Research Institute for Information Science and Technology and the behavioral research ethics board at the University of Ta- briz, Iran. In addition, All athletes filled out written con- sent form.}

\section{Anthropometry}

The weight was determined with accuracy of $0.1 \mathrm{~kg}$, with the least clothing and no shoes, using a portable digital scale (Seca, Germany). Height, waist and hip circumference were recorded to the nearest $1 \mathrm{~cm}$. Body mass index (BMI) was calculated $\left(\mathrm{kg} / \mathrm{m}^{2}\right)$. Then all skinfold measurements were done on the right side of the body as indicated by lange skin caliper. Triplicate measurements were taken to the nearest $1 \mathrm{~mm}$ at the triceps, iliac and abdomen sites, with the mean at each site used to calculate the body fat percentage with Jackson Pollock equation. ${ }^{9}$

\section{Self-reported Food Records}

Nutrient intake data were collected through a self-reported food diary, with records kept for 3 days ( 2 weekdays and 1 weekend day). All participants completed a food diary during the first meeting, which included a lunch time, to ensure that all participants understood the instructions to resolve any difficulties that occurred. All athletes completed the food diaries within one season to avoid seasonal variations in fruits and vegetables. Both a mobile number and an e-mail address were given out, allowing them full guidance and support during the 3-day period by the sports dietitian. Participants recorded food type, amount and cooking method (like fried, grilled and so on), and the time of the intake of materials and drinks in all their meals and snacks. They were also asked to record the brand name and amount consumed of all vitamin/ mineral supplements. Food-record data were analyzed in Nutrition IV software (Diet Analysis Module Version 3.5.2 N-squard computing and first DataBank Division The Hearst Corporation IIII BayHill DR. SAN BRUNO. CA 94066). Food amounts were recorded by the athletes as either household measures or grams. The same measure was then entered into Nutrition IV to calculate Water-soluble vitamins (Thiamin, Riboflavin, Niacin, acid pantothenic, Vitamin B6, Folate, biotin, Vitamin B12, Vitamin C), fat-soluble vitamins (A, D, E and K) and minerals (sodium, potassium, iron, calcium, magnesium, phosphorus, zinc, fluorine, cooper, molybdenum, chromium, manganese). All data were considered by age and gender because DRIs are not the same for vitamins and minerals in males and females in different ages. There are several dietary reference values. The RDA and adequate intake (AI) are the values used in this paper. ${ }^{10} \mathrm{RDA}$ is designed to meet the requirements of at least $97 \%-98 \%$ of healthy population based on a normal distribution. In case of the absence of RDA value, we used AI values as a reference point as described previously. ${ }^{11}$

\section{Data Analysis}

Data were analyzed using the SPSS software version 22.0 (SPSS Inc., Chicago, IL, USA). The normality of the distribution of data was evaluated by the Shapiro-Wilk test. Also the log was used to normalize the data. Descriptive data included means and standard deviations for all variables. Comparison with the standard value was made by one sample $t$ test and comparison between the 2 groups (men and women) by independent $t$ tests. Significance was assumed at $P<0.05$.

\section{Results}

Table 1 shows the mean demographic and anthropometric characteristics of participants by gender. The daily vitamin intake, its comparison with the standard value and the comparison between men and women are shown in Table 2, the same data about minerals are shown in Table 3.

The percent of calories from carbohydrate, protein and fat were $58.87 \%, 14.2 \%$ and $26.75 \%$ in men respectively; while they were $54 \%, 14.18 \%$ and $31.81 \%$ in women. All intakes in men and women were in acceptable macronutrient distribution ranges. Acceptable macronutrient distribution ranges were established for able-bodied adults who were not elite athletes, and were not specific to athletes with disabilities. The average energy intake was $3573.66 \pm 1413.16$ in men and $2191.72 \pm 721.79 \mathrm{Kcal}$ in women.

The intakes of folate, vitamin $\mathrm{K}$, magnesium in men, biotin, vitamin A, calcium in women and vitamin E, D, po- 
Table 1. Demographic and Anthropometric Characteristics of Participants

\begin{tabular}{|c|c|c|c|}
\hline Characteristic & Men (24) & Women (11) & $P$ Value \\
\hline Age $(y)$ & $37.17 \pm 8.69$ & $35.64 \pm 12.38$ & 0.56 \\
\hline Height $(\mathrm{cm})$ & $172.56 \pm 6.79$ & $159.95 \pm 9.46$ & 0.001 \\
\hline Weight $(\mathrm{kg})$ & $77.35 \pm 16.32$ & $57.92 \pm 13.12$ & 0.001 \\
\hline Body mass index (BMI) $\left(\mathrm{kg} / \mathrm{m}^{2}\right)$ & $25.75 \pm 4.07$ & $22.92 \pm 5.67$ & 0.15 \\
\hline Body fat $(\%)$ & $22.56 \pm 5.33$ & $28.69 \pm 6.37$ & 0.01 \\
\hline waist-hip ratio (WHR) & $0.96 \pm 0.06$ & $0.85 \pm 0.06$ & $<0.0001$ \\
\hline Poliomyelitis & $\mathrm{n}=20(83.33 \%)$ & $\mathrm{n}=8(72.72 \%)$ & \\
\hline Amputee & $\mathrm{n}=2(8.33 \%)$ & $\mathrm{n}=2(18.19 \%)$ & \\
\hline Spinal cord injury & $\mathrm{n}=1(4.17 \%)$ & $\mathrm{n}=1(9.09 \%)$ & \\
\hline Visually impaired & $\mathrm{n}=1(4.17 \%)$ & - & \\
\hline
\end{tabular}

Note: Data are present as mean and standard diviation.

Table 2. Mean Intakes (Mean \pm SD) of Vitamins Compared With DRIs and Comparison Between Males and Females

\begin{tabular}{|c|c|c|c|c|c|c|c|}
\hline \multirow{2}{*}{ Vitamins } & \multicolumn{3}{|c|}{ Men $(n=24)$} & \multicolumn{3}{|c|}{ Women $(n=11)$} & \multirow{2}{*}{$P$ Value $^{\text {b }}$} \\
\hline & Intake Value & RDA or $\mathrm{Al} \%$ & $P$ Value ${ }^{a}$ & Intake value & RDA or $\mathrm{Al} \%$ & $P$ Value $^{\mathrm{a}}$ & \\
\hline B1 (mg) & $3.41 \pm 1.99$ & $284.08 \pm 166.15$ & $<0.0001$ & $2.40 \pm 1.28$ & $218.36 \pm 117.26$ & $<0.0001$ & 0.14 \\
\hline B2 (mg) & $2.12 \pm 0.95$ & $163.23 \pm 73.44$ & $<0.0001$ & $1.39 \pm 0.44$ & $126.20 \pm 40.34$ & 0.56 & 0.16 \\
\hline B3 (mg) & $35.90 \pm 12.57$ & $223.86 \pm 78.55$ & $<0.0001$ & $25.11 \pm 8.97$ & $178.90 \pm 64.18$ & $<0.0001$ & 0.02 \\
\hline B6 (mg) & $2.23 \pm 1.01$ & $164.60 \pm 84.37$ & $<0.0001$ & $2.16 \pm 1.08$ & $164.27 \pm 83.88$ & 0.03 & 0.91 \\
\hline Folate (mg) & $290.87 \pm 139.62$ & $72.15 \pm 34.83$ & $<0.0001$ & $351.95 \pm 241.35$ & $87.50 \pm 60.44$ & 0.15 & 0.71 \\
\hline $\mathrm{B} 12(\mathrm{mg})$ & $4.20 \pm 2.25$ & $17.50 \pm 95.01$ & $<0.0001$ & $2.90 \pm 1.17$ & $115.50 \pm 46.53$ & 0.47 & 0.12 \\
\hline Pantothenic acid (mg) & $8.61 \pm 6.62$ & $171.83 \pm 132.51$ & 0.01 & $6.01 \pm 4.05$ & $119.90 \pm 81.25$ & 0.99 & 0.17 \\
\hline Biotin (mg) & $33.52 \pm 23.36$ & $112.79 \pm 79.92$ & 0.41 & $20.39 \pm 12.84$ & $67.36 \pm 42.88$ & 0.01 & 0.11 \\
\hline $\mathrm{C}(\mathrm{mg})$ & $202.53 \pm 200.62$ & $225.70 \pm 222.46$ & 0.03 & $477.72 \pm 418.27$ & $637.18 \pm 557.33$ & 0.02 & 0.19 \\
\hline $\mathrm{D}(\mathrm{mg})$ & $1.45 \pm 1.30$ & $9.78 \pm 8.66$ & $<0.0001$ & $1.16 \pm 0.80$ & $7.37 \pm 5.37$ & $<0.0001$ & 0.55 \\
\hline $\mathrm{K}(\mathrm{mg})$ & $92.07 \pm 71.57$ & $76.25 \pm 59.64$ & $<0.0001$ & $78.46 \pm 77.33$ & $87.14 \pm 85.62$ & 0.13 & 0.97 \\
\hline $\mathrm{A}(\mathrm{RE})$ & $1710.67 \pm 1687.95$ & $189.55 \pm 187.56$ & 0.12 & $508.87 \pm 217.40$ & $72.12 \pm 31.11$ & 0.04 & 0.01 \\
\hline $\mathrm{E}(\mathrm{mg})$ & $7.10 \pm 5.98$ & $46.83 \pm 39.99$ & $<0.0001$ & $6.05 \pm 4.76$ & $39.90 \pm 31.80$ & $<0.0001$ & 0.61 \\
\hline
\end{tabular}

a One sample $t$ test: for comparison vitamins with standard value.

${ }^{\mathrm{b}}$ Independent sample $t$ test: comparison between men and women.

Note: Vitamin K, D, biotin and pantothenic acid comparisons were done on the basis of Al and others on the basis of RDA.

tassium, fluorine, chromium, molybdenum in all athletes were significantly lower than DRIs $(P<0.05)$. Riboflavin, pantothenic acid, B12 and sodium in men and thiamin, niacin, B6, C, phosphorus, iron and cooper in all athletes were significantly above the DRIs $(P<0.05)$. Unlike men, the intake of riboflavin, vitamin B12 and K, pantothenic acid, folate, magnesium and sodium were adequate in women. Vitamin A, biotin and calcium in men and zink, manganese in all athletes were adequate, too. In comparison between men and women, the intake of vitamin B3 (30.05\%), A (70.25\%), calcium (44.58\%), molybdenum (60.99\%) and phosphorus $(24.18 \%)$ in men were significantly higher than women. However fluorine $(29.86 \%)$ and magnesium $(9.15 \%)$ in women were significantly higher than men $(P<0.05) .16 .66 \%$ of men and $18.18 \%$ of women had two meals a day but the others had three meals. $41.66 \%$ of men and $27.27 \%$ of women had no snacks a day.

\section{Discussion}

This is the first study in Iran to report vitamin and mineral intakes of elite paralympic athletes assessing the prevalence of inadequate micronutrient intakes according to the established standards of the DRIs. In this study the intakes of folate, vitamin $\mathrm{K}$, magnesium in men, biotin, vitamin $\mathrm{A}$, calcium in women and vitamin $\mathrm{E}, \mathrm{D}$, potassium, fluorine, chromium and molybdenum in both genders were significantly lower than the DRIs which were similar to various studies. ${ }^{4,5,12-14}$

Calcium is an important structural element in our body. In addition to its cofactor role, the element is also essential for muscle contraction..$^{15}$ In the present study, woman athletes had not adequate calcium intake that was similar to other studies. ${ }^{4,16}$ This is concerning because this nutrient is crucial for general heath and bone integrity, especially for the knees which are the major location affecting performance. ${ }^{2}$ One can obviate such deficiencies by intaking sufficient milk and dairy products at meals.

One of the destructive residues of metabolic cycles in which reactive oxygen species take part is lipid hydro peroxides. It is formed when reactive oxygen, which is generated during physical exercise, reacts with the membrane lipids known as lipid peroxidation. Vitamin E participates as the main antioxidant on cellular surfaces by reducing lipid peroxidation rates which is enhanced by exercising. ${ }^{2}$ The present study showed insufficient vitamin E intake in 
Table 3. Mean Intakes (Mean \pm SD) of Minerals Compared With DRIs and Comparison Between Males and Females

\begin{tabular}{|c|c|c|c|c|c|c|c|}
\hline \multirow{2}{*}{ Minerals } & \multicolumn{3}{|c|}{ Men $(n=24)$} & \multicolumn{3}{|c|}{ Women $(n=11)$} & \multirow{2}{*}{$P$ Value $^{\mathrm{b}}$} \\
\hline & Intake Value & RDA or $\mathrm{Al} \%$ & $P$ Value $^{\mathrm{a}}$ & Intake Value & RDA or $\mathrm{Al} \%$ & $P$ Value $^{\mathrm{a}}$ & \\
\hline Sodium (mg) & $2662.85 \pm 1367.07$ & $179.05 \pm 90.35$ & $<0.0001$ & $1763.65 \pm 1209.19$ & $121.70 \pm 92.72$ & 0.50 & 0.08 \\
\hline Potassium (mg) & $3357.69 \pm 1399.42$ & $70.95 \pm 29.78$ & $<0.0001$ & $2254.63 \pm 612.52$ & $47.72 \pm 12.75$ & $<0.0001$ & 0.01 \\
\hline Iron (mg) & $21.38 \pm 7.31$ & $373.30 \pm 372.73$ & $<0.0001$ & $21.55 \pm 8.19$ & $143.33 \pm 74.56$ & 0.03 & 0.04 \\
\hline Calcium (mg) & $1062.35 \pm 730.32$ & $104.08 \pm 71.86$ & 0.36 & $588.69 \pm 207.12$ & $57.27 \pm 20.30$ & $<0.0001$ & $<0.0001$ \\
\hline Magnesium (mg) & $291.58 \pm 124.99$ & $97.43 \pm 66.03$ & $<0.0001$ & $320.96 \pm 138.70$ & $81.66 \pm 36.34$ & 0.92 & 0.03 \\
\hline Phosphorus (mg) & $1262.20 \pm 325.34$ & $180.00 \pm 46.45$ & $<0.0001$ & $956.97 \pm 258.84$ & $136.09 \pm 37.11$ & $<0.0001$ & $P<0.0001$ \\
\hline Zink (mg) & $10.17 \pm 3.82$ & $112.79 \pm 70.71$ & 0.30 & $10.27 \pm 4.19$ & $103.90 \pm 39.71$ & 0.12 & 0.06 \\
\hline Fluoride(mg) & $196.50 \pm 117.09$ & $7.86 \pm 7.86$ & $<0.0001$ & $280.19 \pm 77.17$ & $6.20 \pm 4.39$ & $<0.0001$ & $<0.0001$ \\
\hline Cooper (mg) & $1.88 \pm 1.22$ & $210.86 \pm 136.02$ & $<0.0001$ & $1.31 \pm 0.55$ & $145.60 \pm 61.81$ & 0.04 & 0.12 \\
\hline Molybdenum (mg) & $20.23 \pm 13.90$ & $44.47 \pm 30.86$ & $<0.0001$ & $7.89 \pm 4.28$ & $17.22 \pm 9.69$ & $<0.0001$ & $<0.0001$ \\
\hline Chromium (mg) & $0.06 \pm 0.05$ & 0.00 & $<0.0001$ & $0.03 \pm 0.01$ & 0.00 & $<0.0001$ & 0.49 \\
\hline Manganese (mg) & $2.09 \pm 0.72$ & $90.90 \pm 31.30$ & 0.23 & $2.24 \pm 0.99$ & $124.27 \pm 55.11$ & 0.16 & 0.07 \\
\hline
\end{tabular}

a One sample $t$ test: for comparison minerals with standard value.

${ }^{\mathrm{b}}$ Independent sample $t$ test: comparison between men and women.

Note: Sodium, potassium, fluoride, chromium and manganese comparisons were done on the basis of $\mathrm{Al}$ and others on the basis of RDA

all of the subjects, which is similar to another research. ${ }^{2}$ This low optimum level may be explained by the poor diet lacking variety. Nuts, for example, are one of the main sources of vitamin $\mathrm{E}$ which are expensive, so they are less consumed.

The findings of this study indicated that the intake of riboflavin, acid pantothenic, B12 and sodium in men and thiamin, niacin, B6, C, phosphorus, iron and copper in both groups was significantly above DRIs $(P<0.05)$ that was similar to other studies with healthy athletes in Iran in many vitamins like vitamin B2, B3, B6, B12, C, D and pantothenic acid. ${ }^{13}$ Also it was similar to another study of niacin, iron and phosphorus. ${ }^{14}$

In the current study, the intake of vitamin B3, A, calcium, potassium, phosphorus and molybdenum in men was significantly higher than those of women and the intake of fluorine, magnesium and iron in women was significantly higher than those of men that was similar to the other study in some variables. ${ }^{4}$

The intake of vitamin A, biotin and calcium in men and vitamin B2, B12, pantothenic acid, folate, vitamin $\mathrm{K}$, sodium and magnesium in women had no differences with the standard value. Also the intake of zinc and manganese was in accordance with DRIs which was similar to the other study in British Paralympic athletes in some micronutrients. ${ }^{6}$ Probably the differences belong to different food culture, price, the amount of the food or the deficiency of some materials in different countries.

\section{Strengths and Limitations}

Repeated measurements of food intakes comprise a major advantage of our study. All participants completed a food diary during the first meeting in the presence of investigators to ensure that they have learned the registration procedure.

Relying on the self-reporting of dietary intakes comprised a limitation of our study. We managed to minimize the effects of this problem by accurately recording food intakes, and having a researcher with the athletes to assist with recording of diaries, clarifying any queries. The other limitation was the scales of the intakes of materials like gram, cups, spoons and so on which we controlled. We recorded the amount of all materials with gram unit in $\mathrm{Nu}$ trition IV software. However, there were some limitations that we could not control. For example,, the probability of concealing the use of banned drugs and the absence or inaccessibility of DRIs for disabled athletes.

\section{Conclusion}

Our study provided a picture on vitamin and mineral intakes and their inadequacies in elite paralympic athletes. However, taking certain vitamins and minerals was in accordance with the standard value in athletes, but the results demonstrated that these athletes are at risk of several micronutrient inadequacies relative to the DRIs. So they should improve their diet choices to meet the standard values for vitamins and minerals.

\section{Ethical Approval}

The study was approved by Iranian Research Institute for Information Science and Technology (Tracking Code: 2302746).

\section{Competing Interests}

Authors declare that they have no competing interests.

\section{Acknowledgments}

The authors would like to thank the Board of Veterans and Disabled of East Azerbaijan province and Ali Kashfiya, a member of the Board of Directors of Paralympic in Iran.

\section{References}

1. Bertoli S, Battezzati A, Merati G, et al. Nutritional status 
and dietary patterns in disabled people. Nutr Metab Cardiovasc Dis. 2006;16(2):100-112. doi:10.1016/j. numecd.2005.05.007.

2. da Silva Gomes AI, Ribeiro BG, de Abreu Soares E. Nutritional profile of the Brazilian Amputee Soccer Team during the precompetition period for the world championship. Nutrition. 2006;22(10):989-995. doi:10.1016/j.nut.2006.05.019.

3. Krempien JL, Barr SI. Risk of nutrient inadequacies in elite Canadian athletes with spinal cord injury. Int J Sport Nutr Exerc Metab. 2011;21(5):417-425. doi:10.1123/ ijsnem.21.5.417.

4. Gerrish H, Pritchett K, Ogan D, Pritchett R, LaCroix M, Broad E. Nutrient intake of elite Canadian and American athletes with spinal cord injury. Int J Exerc Sci. 2016;8(4):17.

5. Eskici G, Ersoy G. An evaluation of wheelchair basketball players' nutritional status and nutritional knowledge levels. J Sports Med Phys Fitness. 2014;56(3):259-268.

6. Goosey-Tolfrey VL, Crosland J. Nutritional practices of competitive British wheelchair games players. Adapt Phys Activ Q. 2010;27(1):47-59. doi:10.1123/apaq.27.1.47.

7. Lukaski HC. Vitamin and mineral status: effects on physical performance. Nutrition. 2004;20(7):632-644. doi:10.1016/j.nut.2004.04.001.

8. Nande P, Mudafale V, Vali S. Micronutrient status of male and female players engaged in different sports disciplines. J Exerc Sci Physiother. 2009;5(1):1-13.
9. Plowman SA, Smith DL. Exercise Physiology for Health Fitness and Performance. Lippincott Williams \& Wilkins; 2013:196-197.

10. Mahan LK, Raymond JL. Krause's Food \& the Nutrition Care Process. Elsevier Health Sciences; 2016:es2-4.

11. Tomey KM, Chen DM, Wang X, Braunschweig CL. Dietary intake and nutritional status of urban communitydwelling men with paraplegia. Arch Phys Med Rehabil. 2005;86(4):664-671. doi:10.1016/j.apmr.2004.10.023.

12. Perret C, Stoffel-Kurt N. Comparison of nutritional intake between individuals with acute and chronic spinal cord injury. J Spinal Cord Med. 2011;34(6):569-575. doi:10.117 9/2045772311Y.0000000026.

13. Daneshvar P, Hariri M, Ghiasvand R, et al. Dietary behaviors and nutritional assessment of young male isfahani wrestlers. Int J Prev Med. 2013;4(Suppl 1):S48.

14. Walters J, Buchholz A, Ginis KM. Evidence of dietary inadequacy in adults with chronic spinal cord injury. Spinal Cord. 2009;47(4):318-322. doi:10.1038/sc.2008.134.

15. Weaver CM. Calcium requirements of physically active people. Am J Clin Nutr. 2000;72(2):579s-584s.

16. Zapolska J, Witczak K, Manczuk A, Ostrowska L. Assessment of nutrition, supplementation and body composition parameters onthe example of professional volleyball players. Rocz Panstw Zakl Hig. 2014;65(3):235242. 